\title{
Editors and Authors: Two Halves of a Whole
}

\author{
Jonathan F. Borus
}

Received: 11 October 2013 / Accepted: 1 November 2013 / Published online: 30 January 2014

(C) Academic Psychiatry 2013

Editors and authors have a reciprocal relationship and neither can prosper without the other. Authors need journals in which to publish and disseminate their work, and editors need interesting content to fill their journals. As such, they have interlocking responsibilities to each other, and in this essay, I will focus on some of these responsibilities from my experiences as an author, reviewer, editorial board member, and the editor of Academic Psychiatry in its early years. I will describe briefly some of the lessons I've learned in these roles with the hope that they will be helpful to both writers and those who lead journals.

An editor has the responsibility to respect the authors who submit their work to his/her journal and to provide them with rapid feedback, accurate and helpful critiques, and clear submission decisions. No author wants to wait months after submission to receive minimal feedback on a paper, and the feedback time frame often hinges on the rapidity of the reviewers doing their work and getting back to the editor. Editors have to respect the time and talents of their reviewers who play a vital role in evaluating submissions, while also having high, clearly delineated, expectations of the reviewers, i.e., that they will perform timely, comprehensive reviews of each assigned paper, write helpful comments to the editor conveying their thoughts about the paper's readiness for publication, and provide detailed comments to the author about the paper's content and ways to make it better. Unlike good wine, reviews do not get easier to perform if aged, and the editor must hold his/her reviewers to a rapid (weeks, not months) review standard. Similarly, a review without substantive comments to the author, no matter how unpublishable the reviewer thinks the paper may be, is a disservice to the author

J. F. Borus $(\bowtie)$

Brigham and Women's Hospital and Harvard Medical School,

Boston, MA, USA

e-mail: jborus@partners.org who should be able to learn from detailed, even if negative, feedback.

Editing and producing a journal is not a one-person affair. In addition to reviewers, editors rely heavily on others to help set the journal's direction, evaluate and process submissions, and do the vital technical work necessary to reliably get the journal published. Most journals have an editorial board which determines the journal's overall direction, deputy, and/or associate editors who help with assignment and assessment of papers, and a skilled editorial administrative staff to process submissions, requests reviews, compile reviewers' feedback, and, when necessary, "hound" anyone in the review process (editors, reviewers, authors) to meet their deadlines. Academic Psychiatry has been fortunate over the years to have had an invested editorial board, a series of excellent editors and deputy/associate editors, a panel of expert reviewers, and outstanding editorial administrative assistance which have allowed it to blossom into one of the leading journals in our field.

Once all reviews are in, the editors read and synthesize them into a publication decision. It is the responsibility of the editor, not the reviewers, to make the ultimate decision about publication and to write a decision letter which clearly lets the author know if the paper has been accepted, if a revision is requested or possible, or if the paper is rejected outright as not fitting the needs of the journal. The editor should strive always to be helpful in his/her feedback, despite the temptation at times to reproach authors who have not fulfilled their responsibilities (see below) before submitting their papers. If the editor communicates with kindness, and when possible provides "teaching feedback" about ways to make the paper better, authors will more likely be able to integrate reasons for the decision, especially if it is a negative one, and use the feedback to improve their writing. I distinctly remember journal editors who were kind to me as a young author, most notably John Nemiah, who, when editor of the American 
Journal of Psychiatry, was known for his explanatory handwritten notes to both authors and reviewers, and I tried to bring some of this benevolence to my editorial work. Since Academic Psychiatry was then a relatively new journal interested in stimulating more high-quality submissions, it was my goal to use the review process to teach authors how to write better papers, a tradition that has continued under subsequent editors; one measure of the success of this strategy has been the increasing number of excellent papers submitted to the journal by psychiatric educators over the years.

Authors have a complementary set of responsibilities to journal editors and reviewers. First, they should become knowledgeable about the process of scholarly writing and review and complete important tasks before submitting their work to a journal $[1,2]$. These include carefully exploring whether their paper is appropriate for the journal to which they are submitting to avoid a mismatch which will waste the time of both the author and the journal. Editors are looking for papers that answer questions or provide innovative ideas relevant to their readers, so authors should read, or at least scan, recent copies of a journal to see what kinds of articles it publishes (scope of topics, type of article: "narrative" or " $p$ value", length restrictions, etc.) and carefully review the journal's "Information for Contributors" so that they can format their paper correctly. The latter is important for many reasons, including the implicit message a paper arriving in the wrong format gives that it has already been rejected by another journal. It still boggles my mind that some authors do not proofread their paper before submitting it, thereby demonstrating inattention to detail that automatically raises questions in the minds of the editor and reviewers about the amount of care taken in the study or program described in the submission.

I strongly suggest that authors seek an internal review from a seasoned writer colleague before submitting a paper. It is easy to "get lost in the trees" of your own work, while a colleague often will be able to see "the forest" and help clarify the paper; it is better to get such feedback from a presubmission internal review than have unclear issues first noted by the reviewers and contribute to a paper not being accepted. Authors also should understand that editors are dealing with space issues. Most good journals are short of space, and a presubmission internal review often can decrease redundancy and shorten the manuscript. It is helpful to the editor for the author to accompany the submission with a brief cover letter describing the paper's contents and focus so that it can be appropriately assigned to those reviewers likely to be most knowledgeable about the paper's topic.

In anticipating the editor's post-review decision letter, authors should understand the review process well enough to know that very few papers are accepted initially by any journal worth its salt. Even in the rare case when an article is accepted on initial submission, most editors will ask the author to read and react to the reviewers' comments and use them to further improve the paper. The majority of articles that receive favorable reviews are not accepted after first submission, but are asked for revision. Authors should consider a request for revision an invitation, a positive response from the editor who must have found something in the article potentially worthy of publication. As an editor, at times, it would have been easier to reject a paper rather than offer the opportunity to revise, in some cases through multiple revisions. However, I enjoyed the opportunity to mentor and nurture Academic Psychiatry's educator authors, help them improve their writing skills, and shepherd promising articles into publishable form.

The author should carefully read all reviews and respond in a revision with those suggested changes he/she believes appropriate and possible to make. As an author, I have not always agreed with reviews of my papers, but most of the time I've found that the feedback can strengthen a revision for resubmission to the same journal or submission elsewhere. It is often helpful for an author to get input from an experienced colleague to fully understand the decision, the reviewers' comments and requests for changes, and also to prereview the revision prior to its resubmission to the journal. In resubmitting, the author has the responsibility to write a cover letter to the editor detailing which changes suggested by the reviewers have, and have not, been made in the revision, with a clear description of the reasons for the latter. In respecting the journal's space and time limits, the author should quickly inform the editor of his/her intention to revise and, if revising, do so rapidly; like reviews, revisions do not get easier to do if left to age. There are many reasons that a paper may be rejected [3], but a wise author will learn from the reviews, revise accordingly, and consider re-aiming the paper towards a more appropriate journal.

Being either an editor or an author is not an easy job, and both require the devotion of an enormous amount of time and effort to be successful. Awareness of, and respect for, the responsibilities of both roles increases the likelihood that innovative educational research and programs will be published and shared with our broader field.

\section{References}

1. Pories S, Bard T, Bell S, Brodsky D, Burns Ewald M, Catic A, Fazio S, Fisher, J, Frontado L, Garfield J, Huang G, Peters A, Pian-Smith M, Quan S, Schwaitzberg S, Borus J. A writer's toolkit. MedEdPORTAL 2012.

2. Roberts L, Coverdale J, Edenharder K, Louie A. How to review a manuscript: a "down-to-earth" approach. Acad Psychiatry. 2004;28: $81-7$.

3. Bordage G. Reasons reviewers reject and accept manuscripts: the strengths and weaknesses in medical education reports. Acad Med. 2001;76:889-96. 